\title{
Characterization of Biofluid-Based Coolant-Mix Produced From Emulsified Groundnut Oils
}

\author{
T. A. Yusuf ${ }^{1 *}$, O. Orihu ${ }^{2}$, T. D. Ipilakyaa ${ }^{2}$ \\ ${ }^{1}$ Mechanical Engineering Deparment, Kyungpook National University, Daegu, South Korea \\ ${ }^{1,2}$ Mechanical Engineering Department, University of Agriculture P.M.B 2373 Makurdi Benue \\ State, Nigeria
}

Received 2 March 2019, accepted in final revised form 9 June 2019

\begin{abstract}
Coolants are generally heat transfer fluids used as cutting fluids for machining or engine cooling. They are generally mixture of various constituents and their chemistry is responsible for their performance, acceptability and shelf lives. With much known about the merit of agro-based materials, this study proposes the use of bio-waters in coolant-mix as a substitute for ordinary water commonly used as base fluids. Water extract from fermented ground maize (WEFGM) employed as bio-water was emulsified in bio-oils (groundnut oils) to form a complete bio-fluid based for the coolant to which other additives are added to form the test solutions. Replicate samples were formulated with similar standards using deionized WEFGM and deionized water for comparison at 5 and $10 \% \mathrm{vol}$ of additives. Following various analytical tests, the developed coolant samples have concentration 2.33$2.58 \mathrm{mg} / \mathrm{L}$, total dissolved solids 31.2-73.2 g/L, $\mathrm{pH} 1.85-2.50$, specific gravity $1.29-1.31$ and viscosity 8.12-11.44 cSt. At both additive concentrations, the biofluid-based samples have proven better in terms of all these properties than water which is generally considered as the most suitable and being currently used as base fluid in most heat transfer applications.
\end{abstract}

Keywords: Biofluids; Heat transfer; Machine coolant; WEFGM; Thermo-physical properties.

(C) 2019 JSR Publications. ISSN: 2070-0237 (Print); 2070-0245 (Online). All rights reserved. doi: http://dx.doi.org/10.3329/jsr.v11i3.40443

J. Sci. Res. 11 (3), 285-292 (2019)

\section{Introduction}

Heat absorptive or transfer properties of fluid is predicated on the physicochemical and thermos-physical nature of their composition and constituent materials [1]. This composition for cutting fluid has been described as being complex [2]. This is so because water-based coolants are inevitably composite fluids with a challenge relating to the selection of materials to form a mixture that would provide the most optimum requirements. The emerging world is fast shifting away from synthetic products on account of various factors such as their carcinogenic influence, non-renewability and non-

\footnotetext{
Corresponding author: yustaofeekay@yahoo.com
} 
biodegradability. Consequently, the use of organic materials, also referred to as biomaterials or agro-based materials are now the most preferred alternatives. The most spectacular of such materials are those regarded as wastes. Their use leads to environmental wellbeing as well as health, economic and industrial benefits. While biowaters extractable from plant sources such as cereals, tubers, fruits etc are significant classes of these wastes, their utility for technological research is still less popular. Quite often, reference to these bio-fluids are limited to animal or human sources listed as blood, sweat, saliva, urine, breast milk etc [3-5] as used in medicine and health sciences.

Against this background, this study considers the use of water extract from fermented ground maize (WEFGM) emulsified in ground nut oils to form a bio-fluid base in a coolant mixture using other selected chemical additives. WEFGM is an organic waste product of virtually all wet-maize food processing. It has most recently been evaluated for various relevant properties that make it a suitable rival to water in terms of viscosity and density. Among its superior qualities is better specific heat capacity [6] as well as possession of corrosion inhibitors and organic glycols which are popular anti-freezing agents [7]. In another finding, it has indicated lower acidity, higher boiling point, higher density, lower viscosity and higher SHC compared to water as synthetic fluids [1].

Groundnut oils is one of the most recommended vegetable oils in the constitution of soluble oils because of its low viscosity which implies high viscosity index and tendency to be fluidic at very high temperature [8]. Comparing the performances of palm oils, groundnuts, their mixtures and conventional mineral-oil based cutting fluids, it was found out that groundnut oils had the least average viscosity of 28.0 Poise and interpreted as having better fluidity and cooling capacity than other fluid samples [9-10]. Consequently, it has been emulsified in WEFGM to form a semi-synthetic solution and improve the lubricity of the mixture together with some other chemical additives. A similar formulation procedure was used for other replicate samples using deionized WEFGM and deionized water to serve as control during tests and analysis.

Morning fresh (a brand of liquid detergent) which contains glycerin was used as emulsifiers. Phosphoric acid ester was employed as corrosion inhibitor, surfactant and extreme pressure additives [1] while formalin was selected as the biocides. Formalin is the common name given to formaldehyde (or methanal) when sold as $37 \%$ aqueous solution [11] or a generic term that describes a solution of $37 \%$ formaldehyde gas dissolved in water [12,13] identified as a commonly used commercial biocides in metalworking fluids. While some authors [11] discourage its use, classifying it as a human carcinogen (cancercausing substance), others [14] see formaldehyde releasing compounds as currently the most significant group of biocides. They specifically remarked that many discussions relating cancer hazard to formaldehyde has not been proven in any existing epidemiological studies. 


\section{Materials and Methods}

\subsection{Materials and equipment}

The materials such as distilled water, groundnut oil and the liquid detergent (used as emulsifier) were sourced locally. The phosphoric acid ester and formalin were sourced at standard chemical stores in Abuja and Makurdi Nigeria respectively while the deionized water was prepared in the laboratory according to standard procedures. The $\mathrm{pH}$ meter (H19811-5), rotational viscosity (NDJ-7), conductivity meter (model S358236 range $100 / 19900$ ) and other equipment used were located in the physics or metallurgy laboratory of Federal University of Agriculture, Makurdi, Nigeria.

\subsection{Methods}

Preparation of WEFGM was carried out in the Metallurgy Laboratory of Mechanical Engineering Department, University of Agriculture, Makurdi (UAM). All other processes and experimental analysis were carried out at Physics Laboratory, UAM at an ambient temperature of $32^{\circ} \mathrm{C}$.

\subsubsection{Preparation of WEFGM}

WEFGM was prepared as described by reference [1] except that the sieving was achieved as one straight process with 300 microns. The modification in the measurement is presented in Table 1.

Table 1. Step-wise procedures and measurements in WEFGM preparation.

\begin{tabular}{llll}
\hline S/N & Process & Measurements & Quantity \\
\hline 1 & Winnowing of Maize Grains & Weight before winnowing & $2400 \mathrm{~g}$ \\
& & Weight after winnowing & $2380 \mathrm{~g}$ \\
2 & Soaking for 72hrs & Volume of distilled water used & $3 \mathrm{~L}$ \\
3 & Draining & Weight after draining & $3400 \mathrm{~g}$ \\
4 & Mechanical milling/Grinding & Volume of distilled water used & $4 \mathrm{~L}$ \\
5 & Sieving (300 microns sieve pan) & Volume of distilled water used & $16 \mathrm{~L}$ \\
6 & Decanting/recovery after 24hrs & Volume of WEFGM & $15 \mathrm{~L}$ \\
\hline
\end{tabular}

\subsubsection{Deionization and formulation of samples}

The first two basic samples were prepared using 90 and 95\%vol of prepared WEFGM samples mixed with 10 and $5 \%$ vol of groundnut oils respectively. Then a similar formula was adopted for both the deionized WEGM and deionized water to make the entire six basic samples used in the study as presented in Table 2. Deionized WEFGM was produced by deionizing a separate portion of WEFGM while deionized water was obtained in the laboratory. Deionization process involved selective removal of all the 
corrosive ions as previously identified in WEFGM [1]. Finally selected additives (biocides, emulsifiers and corrosion inhibitors) were incorporating into these base fluids in 5 and $10 \%$ vol to form the six final experimental samples as presented in Table 3.

Table 2. Formulation of base fluids.

\begin{tabular}{lllllll}
\hline & \multicolumn{2}{l}{ Deionized WEFGM base } & \multicolumn{2}{l}{ Ordinary } & WEFGM base & \multicolumn{2}{l}{ Deionized water } \\
\hline Codes & A90 & A95 & B90 & B95 & C90 & C95 \\
$\begin{array}{l}\text { Water samples } \\
(\% \text { vol })\end{array}$ & 90 & 95 & 90 & 95 & 90 & 95 \\
$\begin{array}{l}\text { Groundnut oils } \\
(\% \text { vol })\end{array}$ & 10 & 5 & 10 & 5 & 10 & 5 \\
\hline
\end{tabular}

Table 3. Composition of fluid samples.

\begin{tabular}{lllllll}
\hline Sample Codes & A90 & A95 & B90 & B95 & C90 & C95 \\
\hline Base Fluid (Water +Groundnut oil), \%vol & 90 & 95 & 90 & 95 & 90 & 95 \\
Emulsifier (Liquid wash) 10\% conc., \% vol & 5 & 2 & 5 & 2 & 5 & 2 \\
Biocide (Formalin) 10\% conc. (\%vol) & 2.5 & 1.5 & 2.5 & 1.5 & 2.5 & 1.5 \\
Phosphate acid ester 10\% conc. (\%vol) & 2.5 & 1.5 & 2.5 & 1.5 & 2.5 & 1.5 \\
\hline
\end{tabular}

\subsubsection{Experimental analysis}

(a) $\mathrm{pH}$, TDS and concentration: The $\mathrm{pH}$ and Total Dissolved Solids (TDS) of the fluid samples were determined using the $\mathrm{pH}$ and conductivity meter. Absorbance and wavelength were measured using spectrophotometer techniques and then followed with the use Beer-Lambert's formula as adopted in reference [1] to determine the concentration except that the Cuvette Path length is $1.7 \mathrm{~cm}$ and absorption coefficient, $e=600 \mathrm{~g} / \mathrm{L}$.

(b) Density and viscosity: The determination of the density was through repeated measurement of mass and volume as adopted in reference [5]. The viscosity of the materials was determined using NDJ-7 rotary viscometer, driven by a miniature synchronous motor at $750 \mathrm{rev} / \mathrm{min}$ and a constant rotational speed (60rev/min), almost independent of load and supply voltage variations. The output of this equipment is dynamic or absolute viscosity, $\mu_{s}$ which is measured in milliPasca seconds, mPa.s $\left(10^{-}\right.$ ${ }^{3} \mathrm{~Pa} . \mathrm{s}$ ) and also called or equivalent to one centiPoise (cP) according to reference [15]. Meanwhile, the viscosities of a working (such as cutting) fluid are often expressed in kinematic viscosity [1] with a popular unit of centistoke (cSt) which is given by

$V_{s}\left(m^{2} / s\right)=\frac{\mu_{s}}{\rho}$

Where $\mu_{s}$ is the dynamic or absolute viscosity of the sample in Pa.s

$\rho$ is the density of the sample in $\mathrm{kg} / \mathrm{m}^{3}$

More so, one centistoke (cSt) is equivalent to $\mathrm{m}^{2} / \mathrm{s} \times 10^{-6}$ [15]. Thus, the experimental output was converted to its kinematic equivalent by modifying Eq. (1) to Eq. (2) 
$V_{s}(c S t)=\frac{\mu_{s}}{\rho} \times 10^{3}$

Where $\mu_{s}$ is expressed in $\mathrm{mPa}$.s or $\mathrm{cP}$.

(c) Specific heat capacity: The specific heat capacity, $\mathrm{C}$ of the fluid sample was determined using the method of mixtures employed in reference [1]. This method involves heating a copper solid ball initially to a certain temperature and then transferring it into the fluid samples inside a calorimeter while recording this initial temperature. The system is left for certain period of time till a significant drop has been observed in the temperature of the copper which implies increase in the temperature of the calorimeter and the samples. It follows the principle of conservation of energy such that heat loss by the copper solid is equal to the sum of heat gained by both the calorimeter and the fluid samples. Eq. (3) implies the specific heat capacity of each of the sample is the ratio of heat change between the solid and the calorimeter to the temperature change of a unit mass of the sample.

$C=\frac{M_{1} C_{1}\left(\theta_{3}-\theta_{2}\right)-M_{2} C_{2}\left(\theta_{2}-\theta_{1}\right)}{M_{3}\left(\theta_{2}-\theta_{1}\right)}$

Where:

$\mathrm{C}_{1}=390 \mathrm{~J} / \mathrm{Kg} / \mathrm{K}$, Specific heat capacity of solid (copper)

$\mathrm{C}_{2}=900 \mathrm{~J} / \mathrm{Kg} / \mathrm{K}$, Specific heat capacity of calorimeter

$\mathrm{m}_{1}=75.5 \mathrm{~g}$, Mass of the solid (copper)

$\mathrm{m}_{2}=$ Mass of the calorimeter

$\mathrm{m}_{3}=$ mass of the fluid samples

$\theta_{1}=$ initial (room) temperature of calorimeter and fluid sample

$\theta_{2}=$ final temperature of the mixtures (after heat transfer into it from the hot copper solid)

$\theta_{3}=$ temperature of the heated copper (solid) ball before its transfer into the mixture.

\section{Results and Discussion}

The various outcomes of the experimental study are presented in Table 4-6.

\subsection{Concentration, TDS and $p H$}

Table 4. Concentration, TDS and $\mathrm{pH}$ of the samples.

\begin{tabular}{llllll}
\hline $\begin{array}{l}\text { Sample } \\
\text { code }\end{array}$ & Fluid Samples & $\begin{array}{l}\text { Absorbance, } \\
\mathrm{A}\end{array}$ & $\begin{array}{l}\text { Concentration, } \\
\mathrm{mg} / \mathrm{L}\end{array}$ & $\begin{array}{l}\mathrm{TDS} \\
\mathrm{g} / \mathrm{L}\end{array}$ & $\begin{array}{l}\mathrm{pH} \\
\text { @ 32 }\end{array}$ \\
\hline A90 & Deionized WEFGM & 2.61 & 2.56 & 34.50 & 2.10 \\
A95 & Deionized WEFGM & 2.57 & 2.50 & 31.20 & 1.87 \\
B90 & Ordinary WEFGM & 2.63 & 2.58 & 73.20 & 2.50 \\
B95 & Ordinary WEFGM & 2.62 & 2.57 & 69.50 & 1.92 \\
C90 & Deionized Water & 2.40 & 2.35 & 58.10 & 2.08 \\
C95 & Deionized Water & 2.38 & 2.33 & 52.20 & 1.85 \\
\hline
\end{tabular}


The fluid samples as shown in Table 4 have concentration 2.33-2.58 mg/L, TDS 31.2-73.2 $\mathrm{g} / \mathrm{L}$ and $\mathrm{pH}$ 1.85-2.50. Concentration has been defined as the ratio of solute (dissolved particulate solids) to either solvent or total solution [16]. TDS, according to [17] is used to describe inorganic salts and small amount of organic matter present in solution. With the remark of these last authors that the $\mathrm{pH}$ is affected by chemicals in solution, it may be logical to conclude that the three parameters are interrelated and that one significantly affects the other but statistical correlation result using IBM SPSS software version 23 indicated otherwise $(\mathrm{p}>0.05)$. According to them, TDS is inversely related to $\mathrm{pH}$, an assertion that can neither be vividly established in this result nor in the output of a similar study carried out in reference [1]. The $\mathrm{pH}$ is an important property of a heat transfer fluid as it influences corrosion when outside the range of 6.5-8.5 [18] or 7.0-9.5 [1]. However, adjustment of $\mathrm{pH}$ values is a regular task in heat transfer fluids which has been undertaken by researchers like [19]. The observed $\mathrm{pH}$ of all the samples are highly acidic as clearly indicated in Table 6 but samples with WEFGM and deionized WEFGM as base fluids even appear better than that of the deionized water. The values fall within the typical $\mathrm{pH}$ values for Hydrochloric acid and other organic products such as lemon juice and vinegar [20]. Meanwhile, the result has indicated that low $\mathrm{pH}$ in the WEFGM associated fluids in this case may not be significantly related to the accumulated organic acid products of fermentation process as reported by [21]. Otherwise, fluids that are based on deionized water are not expected to be more strongly acidic (i.e. having lower $\mathrm{pH}$ ) than those based on WEFGM. Besides, pure WEFGM have been found to be weakly acidic and reported with a much higher $\mathrm{pH}$ of 6.24-6.30 [21] or 2.67-2.82 [7]. Considerably, the $\mathrm{pH}$ of the samples are higher than 1.01-1.41 reported in reference [1] for synthetic fluids. This may imply that the presence of oils in this composition might have contributed to improved $\mathrm{pH}$ which may indirectly be an explanation for why oils are poorer agents of corrosion than waters. Nevertheless, this finding conforms to the findings of the same authors that WEFGM is better in terms of $\mathrm{pH}$ as base fluids in coolant-mix than water.

\subsection{Density and viscosity}

Table 5. Density and viscosity of the samples.

\begin{tabular}{|c|c|c|c|c|c|c|c|}
\hline \multirow[b]{2}{*}{$\mathrm{S} / \mathrm{N}$} & \multirow[b]{2}{*}{ Codes } & \multirow[b]{2}{*}{$\begin{array}{l}\text { Volume } \\
(\mathrm{mL})\end{array}$} & \multirow[b]{2}{*}{$\mathrm{M}_{\mathrm{f}}(\mathrm{g})$} & \multirow[b]{2}{*}{$\begin{array}{l}\mathrm{M}_{\mathrm{s}} \\
\left(M_{f}-M_{e}\right) \mathrm{g}\end{array}$} & \multirow[b]{2}{*}{$\begin{array}{l}\text { Density, } \rho \\
\left(\mathrm{kg} / \mathrm{m}^{3}\right)\end{array}$} & \multicolumn{2}{|c|}{ Viscosity } \\
\hline & & & & & & $\begin{array}{l}\text { Dynamic, cP } \\
\text { (or mPa.s) }\end{array}$ & Kinematic, cSt \\
\hline 1 & A90 & 300 & $903.8 \pm 0.03$ & $390.3 \pm 0.03$ & 1300.9 & $12 \pm 0.1$ & 9.22 \\
\hline 2 & A95 & 300 & $903.9 \pm 0.06$ & $390.4 \pm 0.06$ & 1301.0 & $11.5 \pm 0.2$ & 8.84 \\
\hline 3 & B90 & 300 & $904.2 \pm 0.13$ & $390.7 \pm 0.13$ & 1301.9 & $14.9 \pm 0.1$ & 11.44 \\
\hline 4 & B95 & 300 & $905.4 \pm 0.02$ & $391.9 \pm 0.01$ & 1306.3 & $12.6 \pm 0.1$ & 9.65 \\
\hline 5 & C90 & 300 & $900.5 \pm 0.02$ & $387 \pm 0.01$ & 1289.9 & $10.8 \pm 0.1$ & 8.37 \\
\hline 6 & $\mathrm{C} 95$ & 300 & $901.4 \pm 0.12$ & $387.9 \pm 0.7$ & 1293.3 & $10.5 \pm 0.1$ & 8.12 \\
\hline
\end{tabular}


Table 5 shows the specific gravity of the fluids as $1.29-1.31$ and viscosity as $8.12-11.44$ cSt. Low viscosity but high density is desired for heat transfer fluids since according to [22], low viscosity improves heat transfer while low density reduces it. According to the report, viscosity have the most superior influence, followed by density, then specific heat and lastly by thermal conductivity in order of significance. Consequently, this result indicates that the fluids whose base fluids are WEFGM and deionized WEFGM are denser but less viscous than that based on deionized water. The lower density of deionized waterbased fluid samples may be due to its lower concentration as read on Table 4. Statistical T-test shows that there is no significance difference in viscosities of the samples ( $\mathrm{p}>$ 0.05 ) but it exists between the densities of WEFGM-based and deionized water-based fluid samples $(\mathrm{p}=0.025)$. This further favours WEFGM over water as previously reported by $[1,6]$.

\subsection{Specific heat capacity}

Table 6. Specific heat capacity of the samples.

\begin{tabular}{llllllll}
\hline Base fluids & $\begin{array}{l}\text { Sample } \\
\text { Codes }\end{array}$ & $\theta_{1}\left({ }^{\circ} \mathrm{C}\right)$ & $\theta_{3}\left({ }^{\circ} \mathrm{C}\right)$ & $\theta_{2}\left({ }^{\circ} \mathrm{C}\right)$ & $m_{2}(g)$ & $m_{3}(g)$ & $\begin{array}{l}\text { Specific heat } \\
\text { capacity, } \mathrm{C}\left(\mathrm{kg}^{\circ} \mathrm{K}\right)\end{array}$ \\
\hline Deionized WEFGM & A90 & 32 & 95 & 43 & 217.20 & 216.90 & -259.5 \\
Deionized WEFGM & A95 & 33 & 94 & 41 & 211.00 & 210.60 & 24.56 \\
WEFGM & B90 & 32 & 95 & 41 & 229.90 & 226.20 & -133.7 \\
WEFGM & B95 & 33 & 91 & 41 & 204.30 & 202.30 & 0.797 \\
Deionized water & C90 & 33 & 94 & 45 & 210.60 & 208.60 & -332.2 \\
Deionized water & C95 & 34 & 93 & 42 & 212.00 & 210.80 & -14.65 \\
\hline
\end{tabular}

The specific heat capacity of the fluids as shown in Table 6 is higher for WEFGM-based and deionized WEFGM-based fluids than deionized water-based sample. This also agrees with $[1,6]$ who reported that WEFGM is better in terms of specific heat capacity than water.

\section{Conclusion}

Attempt has been made to formulate coolant-mixture using water extract from fermented ground maize (WEFGM), an agro waste and groundnuts oils as based fluids which are purely organic products. It was tested along with a conventional sample formulated using water. Results indicated that organic water has better influence on the selected properties of the samples than water which is generally considered as the most suitable and currently used as base fluid in most heat transfer applications. The samples with former as base fluids show less acidity as well as higher viscosity and specific heat capacity.

\section{References}

1. T. A. Yusuf, J. Z. Atsehekaa, and M. L. Baka, J. New Techn. Matr. 8, 15 (2018). https://doi.org/10.12816/0048921 
2. S. A. Lawal, I. A. Choudhury, and Y. Nukman, (2012). https://www.semanticscholar.org/paper/Application-of-vegetable-oil-based-metalworking-inLawal-Choudhury/c0da1b058e59961d96f5d66b761db07baaa708ff (accessed on June 9, 2019).

3. Biofluids, IIHR-Hydroscience and Engineering (The University of Iowa, Maxwell Stanley Hydraulics Laboratory, Iowa City, Lowa, 52242-1585). www.iihr.uiowa.edu/research/biofluids

4. W. C. Shiel Jr, Medical Definition of Biofluid. https://www.medicinenet.com/weight_gain/symptoms.htm

5. P. Nithiarasu, Biofluid Dynamics (Swansea University, Swansea, UK). https://www.maths.gla.ac.uk>Arasu-biofluid.pdf

6. T. A. Yusuf, B. O. Bolaji, S. O. Ismaila, and J. K. Adewumi, Silpakorn Univ. Sci. Technol. J. 10, 51 (2016).

7. T. A. Yusuf, B. O. Bolaji, and S. O. Ismaila, Walailak J. Sci. Technol. 14, 75 (2017).

8. M. Susmitha, P. Sharan, P. N. Jyothi, IOP Conf. Series: Mater. Sci. Eng. 149, 1 (2016). https://doi.org/10.1088/1757-899X/149/1/012037

9. S. K. Kolawole and J. K. Odusote, Chem. Matr. Res. 3, 35 (2013).

10. S. A. Lawal, M. S. Abolarin, B. I. Ugheoke, and E.O. Onche. http://lejpt.academicdirect.org/A10/137 144.htm

11. Encyclopedia Britannica,Formaldehyde Chemical Compounds, Encyclopadia Britannica, Inc. https://www.britannica.com/science/formaldehyde

12. Water Sampling and Testing for Formaldehyde at Northwest Fish Hatcheries. https://www.epa.gov/sites/production/files/2017-09/documents/water-sampling-formaldehydenw-fish-hatcheries-report-2017.pdf (accessed on June 9, 2019)

13. S. B.Selvaraju, I. U. H. Khan, and J. S. Yadav, Appl. Env. Microbio. 71, 542 (2005). https://doi.org/10.1128/AEM.71.1.542-546.2005

14. Lubricants and Lubrications, ed. T. Mang et al. (Wiley VCH, Germany, 2017). https://books.google.com.ng/books?id=4I2bCgAAQBAJ\&pg=PA543\&dq (accessed on 9/06/2019)

15. T. A. Yusuf, M. Eng. Thesis, Federal University of Agriculture Abeokuta, Ogun State Nigeria, 2014.

16. A. M. Helmenstine, Concentration Definition (Chemistry), In IUPAC, Compendium of Chemical Terminology (2019). https://www.thoughtco.com/definition-of-concentration605844 (accessed on June 9, 2019).

17. R. Islam, S. M. Faysal, M. R. Amin, F. M. Juliana, M. J. Islam, M. J. Alam, M. N. Hossain, and M. Asaduzzaman, J. Nurs. Health Sci. 6, 35 (2017).https://doi.org/10.9790/1959$\underline{0601083539}$

18. H. H. Oyem, I. M. Oyem, D. Ezeweali, Res. J. Env. Sci. 8, 444 (2014). https://doi.org/10.3923/rjes.2014.444.450

19. G. Narenda, A. V. S. S. K. S. Gupta, A. Krishnaiah, and M. G.V. Satyanarayana, Mater. Today: Proceed. 4, 3926 (2017). https://doi.org/10.1016/j.matpr.2017.02.292

20. Proper Fluid Selection and Maintenance for Heat Transfer Applications, Technical Note, ed. S. Pratt et al. (Thermo Fisher scientific, Newington, New Hamsphire). https://assets.thermofisher.com/TFS-Assets/LSG/brochures/Proper-fluid-selectionmaintenance-for-heat-transfer-TNTCFLUIDS.pdf (accessed on June 9, 2019).

21. T. A. Yusuf, D. T. Gundu, M. I. Oseni, B. O. Bolaji, and S. O. Ismaila, Int. J. Eng. Sci, 2, 31 (2013).

22. Special Report Heat Transfer Fluids: Do's, Don'ts, and Best Practices. https://www.chemicalprocessing.com/assets/wp_downloads/pdf/Paratherm_eBook_110324.pdf (accessed on June 9, 2019). 